\title{
Three heart medications in short supply in Canada
}

A national shortage of two drugs used to treat cardiac arrhythmia, along with the end of special access to a third, has left patients and their doctors scrambling to find alternatives in Quebec, Ontario and Saskatchewan.

The manufacturers of the brand name and generic versions of propafenone and flecainide have listed these drugs on Health Canada's Canadian Drug Shortage Database. A third drug, dofetilide (Tikosyn), was available through Health Canada's Special Access Programme, but was withdrawn in September 2013. According to Health Canada, the program only stocks drugs for short-term and emergency use.

Although Health Canada has confirmed the shortage of flecainide in the Montréal, Quebec area, a spokesperson was unaware of the more general shortage.

"Health Canada has followed up with the company and has been advised that the product [flecainide] is on backorder, with an estimated resupply date of mid-February," Leslie Meerburg wrote CMAJ in an email. "In the meantime, the [manufacturer] is working to find supply in the supply chain and redirect some product to the region in shortage."

The shortage of propafenone may have led to the shortfall of flecainide. For instance, medSask, a Saskatchewan drug information program, was recommending flecainide as an alternative to propafenone when that drug ran out, says Carmen Bell, a pharmacist with the service. That recommendation likely placed extra demand on supplies of flecainide, she added.

Whatever the cause, the concurrent shortages of all three medications is unfortunate, says Dr. Eugene Crystal, director of Arrhythmia Services at Sunnybrook Health Sciences Centre in Toronto, Ontario. "The impact is very significant because many of these patients are totally dependent on these medications."

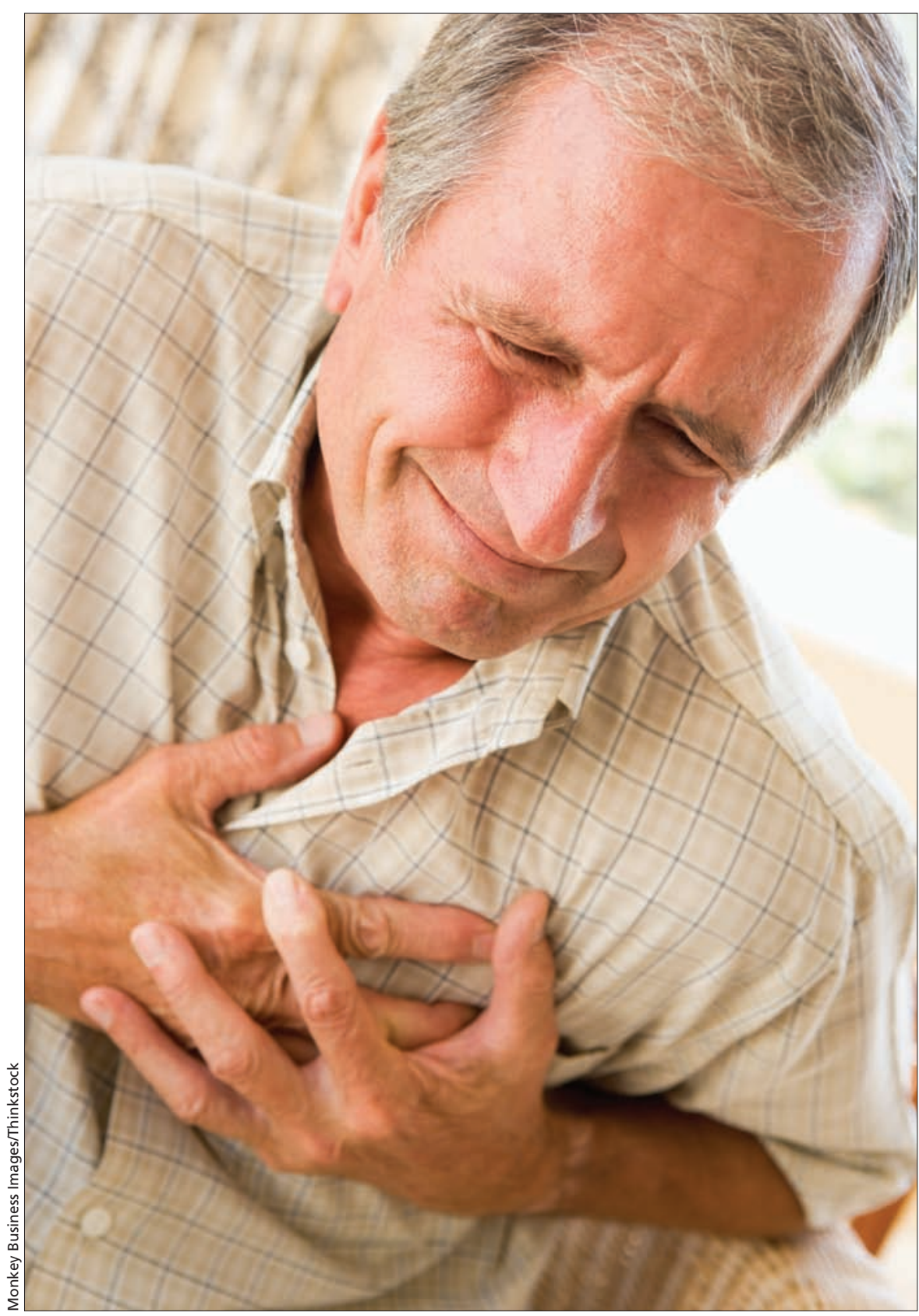

A concurrent shortage of propafenone, flecainide and dofetilide is problematic, according to experts.

Most of the patients for whom Crystal was prescribing flecainide, propafenode or dofetilide have atrial fibrillation, the most common type of irregular heart arrhythmia. Without medication their arrhythmia recurs, he says.

Although atrial fibrillation is rarely life-threatening, being without these medications "may damage their wellbeing to a significant extent, in particular because we are left almost without alternatives," Crystal says.

His fallback drug is amiodarone, an older drugt that Crystal describes as 
"the most toxic" antiarrhythmic with "multiple side effects."

Many of Crystal's patients are forced to go to multiple compounding pharmacies which have some propafenone that they prepare, he says.

Crystal expects more patients requiring these drugs will be seen in emergency departments. "Our offices are becoming a little busier as we are trying to change medications and many of these patients are only responding to one or two medications. It's very problematic."

In Montréal, a cardiologist with the McGill University Health Centre also reports that many of his patients are running out of flecainide.

AA Pharma Inc., the Toronto-area generic pharmaceutical company that produces the drug, did not return repeated calls from CMAJ. However, the company did post a notification of the shortage on the Canadian Drug Shortages Database at Health Canada's request.

Tambocor, the brand-name version of flecainide, is also in short supply, according to its manufacturer, which listed it on the drug shortage database on Jan. 29.

According to Health Canada, propafenone is the only available antiarrhythmic drug in the same class as flecainide. But generic manufacturer Sanis Health Inc. has also listed propafenone as being in short supply, with no known resupply date.

A spokesperson for Abbott Laboratories, which manufactures Rythmol, the brand-name version of propafenone, confirmed that there is a market-wide shortage of propafenone hydrochloride, but said the company would have a new supply available by the end of February. "Rythmol results from a complex manufacturing process," Hind Ounis, Abbott's communications manager in Montréal, said. When pressed about the reasons for the shortage, she attributed it to "excess demand."

"There are several other alternative antiarrhythmic agents of different classes marketed in Canada that can be used to initiate therapy in newly diagnosed patients," Health Canada's Meerburg wrote. - Laura Eggertson, Ottawa, Ont.

CMAJ 2014. DOI:10.1503/cmaj.109-4723 